\title{
Tendência familial das fissuras lábio-palatais
}

\author{
José Alberto de SOUZA-FREITAS*, Gisele da Silva DALBEN**, Patrícia Zambonato FREITAS***, \\ Milton SANTAMARIA JR. ${ }^{\star \star \star *}$
}

\begin{abstract}
Resumo
Este estudo visou investigar a porcentagem de pacientes com fissuras que relatam a existência de casos anteriores de indivíduos com fissuras ou outras anomalias congênitas na família. Foram entrevistados 803 pacientes com fissura de lábio e/ou palato, com ou sem más formações adicionais e sem síndromes reconhecíveis; as informações foram analisadas em porcentagens e médias. Uma porcentagem significante da amostra (32,3\%) apresentou um ou mais casos de indivíduos com anomalias na família, com uma influência notável da presença de irmãos com fissuras e parentes com tipos mais severos de fissuras. Os resultados sugerem a presença da herança entre os prováveis fatores etiológicos. Todos os profissionais da saúde devem estar cientes deste fato para possibilitar o fornecimento de informação e aconselhamento.
\end{abstract}

Palavras-chave: Anormalidades congênitas. Fissuras lábio-palatais. Hereditariedade.

\section{INTRODUÇÃO}

A fissura lábio-palatal é uma das más formações congênitas mais comuns no ser humano, afetando cerca de 1 em cada 650 nascidos vivos ${ }^{13}$. Sua etiologia é bastante complexa e definitivamente multifatorial, ou seja, pode envolver tanto fatores genéticos como ambientais em conjunto. Esta característica torna difícil o estabelecimento da origem verdadeira desta anomalia em muitas famílias que procuram aconselhamento genético após o nascimento de um bebê com fissura, o que impede o desenvolvimento de programas preventivos confiáveis.

Muitos fatores relacionados à etiologia das fissuras orofaciais têm sido investigados e os autores têm encontrado resultados controversos. Greene et al. $^{7}$ observaram uma relação entre a ocorrência de fissura e baixo peso ao nascimento, gestações gemelares, presença de más formações adicionais e pais mais velhos. Fonseca e Rezende ${ }^{6}$ encontraram uma relação entre o tipo de fissura e o tipo sanguíneo, sendo o $\mathrm{O}+$ o mais prevalente. Estes autores não observaram qualquer relação entre a ocorrência de fissura e a idade dos pais, diferença de idade entre os pais e peso ao nascimento.

Jensen et al. ${ }^{9}$ realizaram um estudo no qual observaram que $7 \%$ da amostra de indivíduos com fissuras relataram a ocorrência de casos anteriores de fissuras na família. Menegotto e Salzano ${ }^{11}$ não encontraram qualquer tendência com relação ao período de nascimento, mas seu estudo revelou uma possível relação entre a ocorrência de fissura e gestação gemelar, baixo peso ao nascimento, ordem de nascimento, uso de drogas (especialmente con-

* Doutor em Radiologia Odontológica, Titular do Departamento de Estomatologia da Faculdade de Odontologia de Bauru (FOB/USP); Superintendente do Hospital de Reabilitação de Anomalias Craniofaciais da Universidade de São Paulo (HRAC/USP), Bauru, SP.

** CD, Especialista em Odontopediatria. Mestre em Fissuras Orofaciais. Cirurgiã-dentista do HRAC/USP, Bauru, SP.

*** CD, Mestre em Ortodontia. Doutoranda em Patologia Bucal, ortodontista do HRAC/USP, Bauru, SP.

$\star \star \star \star \quad C D$, Mestre em Ortodontia. 
traceptivos e hormônios), doenças agudas e crônicas, inclusive a gripe comum.

Slavkin ${ }^{15}$ realizou uma revisão de literatura para procurar a causa do aumento na prevalência de fissura lábio-palatal ao longo do tempo. O autor mencionou associações entre fatores genéticos (gene MHC) e ambientais (utilização de ácido retinóico, esteróides e drogas anticonvulsivantes). De acordo com este autor, 20\% das fissuras têm uma origem genética e muito possivelmente os fatores ambientais em humanos seriam o álcool, ácido retinóico, má nutrição, gravidez após os 35 anos de idade, fumo, acompanhamento pré-natal precário, ingestão de drogas e medicamentos. Com relação ao risco de uma família ter um bebê com fissura, o autor afirmou um risco de $2 \%$ a $4 \%$ se a família já tem outro filho com fissura, e $4 \%$ a $5 \%$ se um dos pais é um indivíduo com fissura. Para prevenção das fissuras orofaciais, o autor recomendou acompanhamento pré-concepcional e pré-natal e aconselhamento genético para famílias com casos anteriores de fissuras.

Collares et al. ${ }^{5}$ não observaram qualquer relação entre a ocorrência de fissura, idade dos pais, consangüinidade ou presença de casos anteriores na família com qualquer tipo de anomalia congênita. No mesmo ano, Murray et al. ${ }^{12}$ observaram um maior risco de recorrência, de 23 em 1000 para a fissura de lábio com ou sem fissura de palato, em relação a 14 em 1000 para a fissura isolada de palato.

Hagberg et al. ${ }^{8}$ encontraram que 26,2\% de uma amostra de pacientes com fissuras relataram a ocorrência de outros indivíduos com fissuras na família, bem como uma relação com o baixo peso ao nascimento. Chuangsuwanich et al. ${ }^{4} \mathrm{ob}-$ servaram uma porcentagem notável de ingestão de drogas pela mãe durante a gravidez (578 em 593) e uma taxa de $21,6 \%$ da amostra com parentes de primeiro ou segundo grau com fissura lábio-palatal.

Lieff et al. ${ }^{10}$ não puderam determinar qualquer relação definitiva entre o tabagismo e a ocorrên- cia de fissura lábio-palatal sem más formações adicionais. No mesmo ano, Carmichael e Shaw ${ }^{3}$ observaram uma relação positiva entre a ocorrência de fissura e a ingestão de drogas corticosteróides durante o primeiro trimestre de gravidez. Alemran et al. ${ }^{1}$ procuraram correlacionar a ocorrência de fissuras com a morfologia craniofacial dos pais, e encontraram diferenças significantes que apontam a necessidade de desenvolver estudos adicionais neste assunto.

Rajabian e Sherkat ${ }^{14}$ encontraram uma relação positiva entre a consangüinidade e a existência de parentes sem fissuras com outros tipos de más formações. Carinci et al. ${ }^{2}$ afirmaram que a fissura de lábio com ou sem fissura de palato é uma anomalia congênita diferente da fissura de palato, desta forma apresentando padrões hereditários diferentes.

\section{MATERIAL E MÉTODOS}

Este estudo envolveu um total de 803 pacientes não operados que compareceram ao Hospital de Reabilitação de Anomalias Craniofaciais da Universidade de São Paulo (HRAC/USP), em Bauru, SP, durante o ano de 2000, independentemente de gênero e raça, sem tratamento cirúrgico prévio, e sem síndromes reconhecíveis, com exceção daqueles casos com fissuras medianas, que geralmente ocorrem em pacientes sindrômicos.

Os pacientes ou seus responsáveis foram indagados sobre a existência de parentes com fissura lábio-palatal ou outros tipos de más formações. Sempre que a resposta fosse "sim", o examinador registrava o número de parentes com más formações, o grau de parentesco entre o paciente e estes parentes e o tipo de má formação apresentado pelo parente. Em alguns casos, o tipo exato de má formação não pôde ser investigado, uma vez que todas as informações foram fornecidas pelos pacientes e/ou responsáveis, sendo então classificada como "fissura não especificada".

As informações foram calculadas em porcentagens e médias. 


\section{RESULTADOS E DISCUSSÃO}

A idade média da amostra foi de 2,8 anos, variando de 6 dias a 49 anos. A maior parte dos pacientes era do gênero masculino (55\%) e da raça branca ou branca não caucasiana $(93,4 \%)$, mas também houve alguns indivíduos melanodermas e xantodermas. A maioria dos pacientes pertencia ao nível sócio-econômico baixo $(71,4 \%)$.

Com relação à investigação de outros casos de indivíduos com fissura lábio-palatal nas famílias

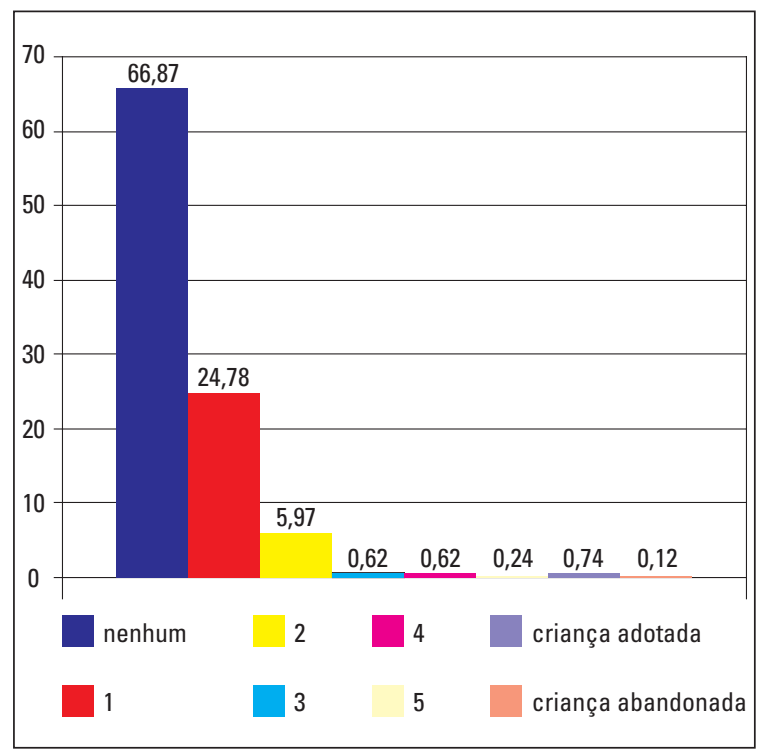

Gráfico 1 - Quantidade de parentes com anomalias entre os pacientes examinados.

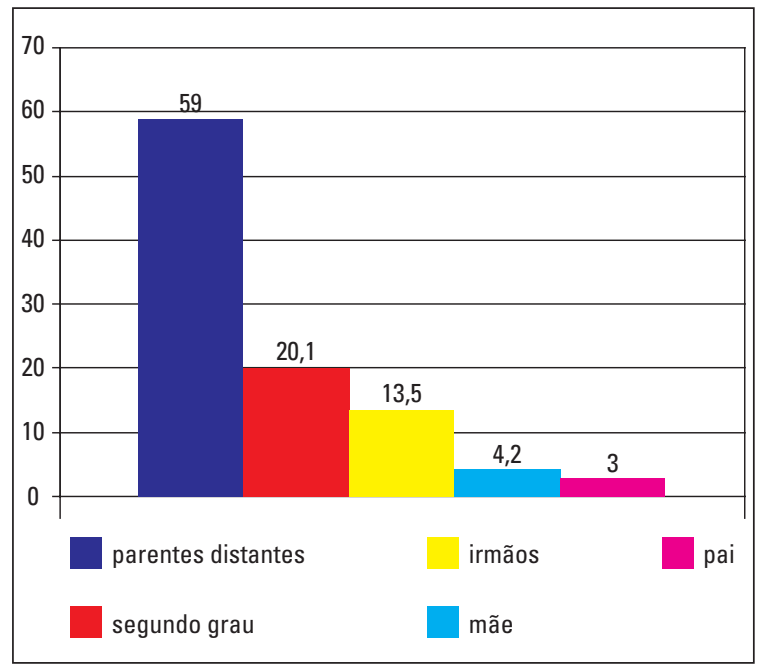

Gráfico 2 - Grau de parentesco dos parentes com anomalias. destes pacientes, foi encontrado que 32,3\% dos pacientes relataram a existência de pelo menos mais um indivíduo com fissura na família. A maioria dos pacientes relatou ter um caso anterior de fissura na família, mas alguns pacientes relataram a ocorrência de até 5 outros casos de fissuras na família (Gráf. 1). Estas informações confirmam a tendência hereditária da anomalia como um dos prováveis fatores etiológicos, em acordo com outros estudos na literatura ${ }^{4,8,9,12,15}$.

Alguns parentes com anomalias tinham uma relação familiar muito próxima aos pacientes desta amostra (Gráf. 2). Houve uma maior porcentagem de mães que pais na população de parentes com fissuras $(4,2 \%$ e $3 \%$, respectivamente). A porcentagem de irmãos com fissuras foi alta $(13,5 \%)$ e incluiu dois pares de gêmeos. Estes valores significam que $1,7 \%, 1,24 \%$ e $5,6 \%$ da amostra total

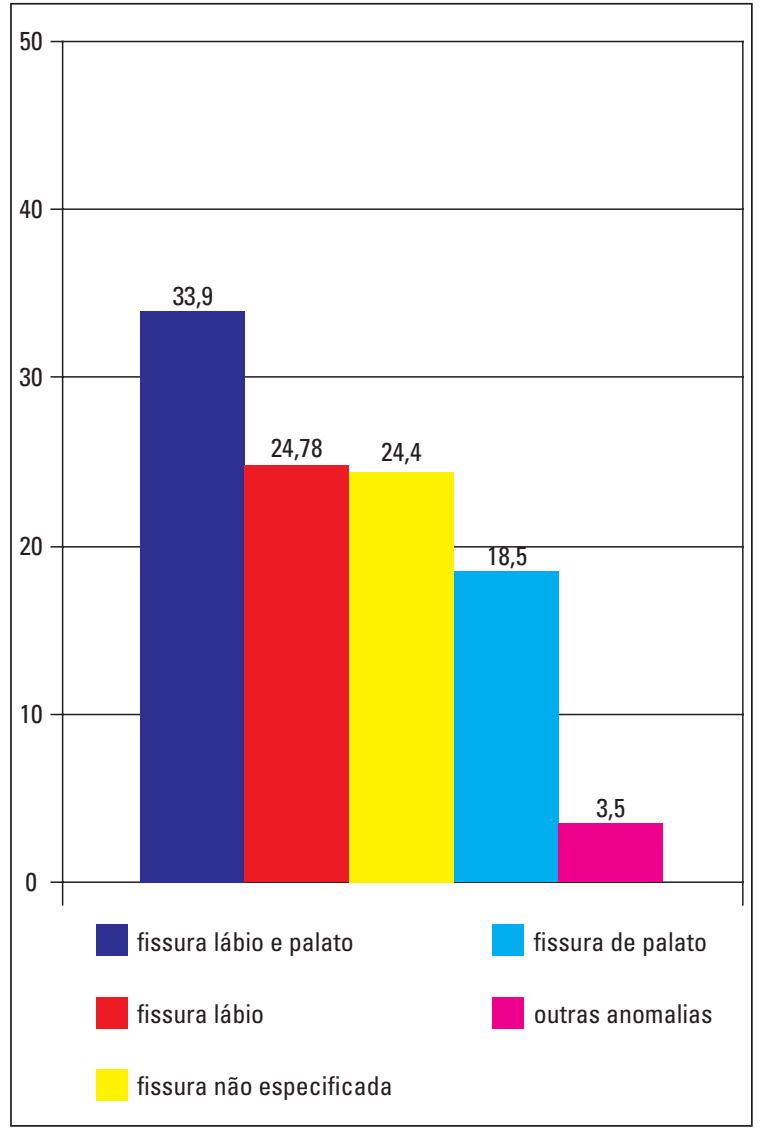

Gráfico 3 - Tipo de anomalia apresentada pelos parentes. 
tinham mães, pais e irmãos com fissuras, respectivamente. Este achado revela o risco acentuado de recorrência de fissuras em famílias com um progenitor ou outra criança afetada pela fissura.

Os parentes de segundo grau incluíram tios, tias e avós. Esta categoria representou 20,1\% do grupo de parentes com anomalias. Parentes distantes foram predominantes (59\%) e incluíram vários tipos de parentesco até parentes de quinto grau.

O tipo de anomalia apresentado pelos parentes, de acordo com a informação fornecida pelos pacientes ou seus responsáveis, foi principalmente fissura lábio-palatal 33,9\%. Este achado poderia sugerir um maior risco de recorrência de fissuras entre indivíduos com fissuras mais severas, que exigiria investigação adicional. Uma pequena porcentagem dos parentes era de indivíduos sem fissuras lábio-palatais com diversos outros tipos de anomalias congênitas (3,5\%) (Gráf. 3).
Os achados deste estudo sustentam a etiologia hereditária da fissura, de acordo com muitos estudos na literatura. Todos os profissionais de saúde devem estar cientes deste fato ao lidar com famílias com casos anteriores de fissuras e anomalias congênitas, para oferecer informação e aconselhamento.

\section{CONCLUSÕES}

1) Uma porcentagem significante da amostra apresentou um ou mais parentes com anomalias $(32,3 \%)$.

2) Foi encontrada uma correlação positiva para a recorrência de fissuras em irmãos, assim atenção especial deve ser dada a casais com um filho portador de fissura.

3) As fissuras mais severas parecem ter uma maior influência hereditária que os outros tipos de fissuras, mas este achado requer investigação adicional.

\title{
Familial tendency of oral clefts
}

\begin{abstract}
This study aimed at investigating the percentage of patients with clefts reporting the existence of previous cases of individuals with clefts or other congenital anomalies in the family. A total of 803 patients presenting cleft lip and/or palate, with or without additional malformations and with no recognizable syndromes were interviewed; data were analyzed in percentages and means. A significant percentage of the sample $(32.3 \%)$ presented one or more cases of individuals with anomalies in the family, with a remarkable influence from the presence of siblings with clefts and relatives with more severe types of clefts. The results suggest the presence of inheritance among the probable etiologic factors. All health professionals should be aware of this fact, in order to be able to provide information and counseling.
\end{abstract}

Key words: Cleft lip and cleft palate. Congenital abnormalities. Heredity. 


\section{REFERÊNCIAS}

1. ALEMRAN, S. E. S.; FATANI, E.; HASSANAIN, J. E. Craniofacial variability in parents of children with cleft lip and cleft palate. J Clin Pediatr Dent, Birmingham, v. 23, no. 4, p. 337-341, Summer 1999.

2. CARINCl, F. et al. Genetics of nonsyndromic cleft lip and palate: a review of international studies and data regarding the Italian population. Cleft Palate Craniofac J, Pittsburgh, v. 37, no. 1, p. 33-40, Jan. 2000

3. CARMICHAEL, S. L.; SHAW, G. M. Maternal corticosteroid use and risk of selected congenital anomalies. Am J Med Genet, New York, v. 86, no. 3, p. 242-244, Sept.1999.

4. CHUANGSUWANICH, A. et al. Epidemiology of cleft lip and palate in Thailand. Ann Plast Surg, Boston, v. 41, no, 1, p. 7-10, July 1998

5. COLLARES, M. V. M. et al. Fissuras lábio-palatinas: incidência e prevaçência da patologia no Hospital de Clínicas de Porto Alegre. Um estudo de 10 anos. Rev AMRIGS, Porto Alegre, v. 39, n. 3, p. 183-188, jul./set. 1995.

6. FONSECA E. P. REZENDE, J.R. V. Incidência das malformações do lábio e do palato. Rev Fac Odontol São Paulo, São Paulo, v. 9, n. 1, p. 45-58, jan./jun. 1971.

7. GREENE, J. C. et al. Epidemiologic study of cleft lip and cleft palate in four states. J Am Dent Assoc, Chicago, v. 68, p. 387404, Mar. 1964.
8. HAGBERG, C.; LARSON, O.; MILERAD, J. Incidence of cleft lip and palate and risks of additional malformations. Cleft Palate Craniofac J, Pittsburgh, v. 35, no. 1, p. 40-45, Jan. 1997.

9. JENSEN, B. L. et al. Cleft lip and palate in Denmark, 1976-1981: epidemiology, variability, and early somatic development. Cleft Palate J, Baltimore, v. 25, no. 3, p. 258-269, July 1988.

10. LIEFF, $S$. et al. Maternal cigarette smoking during pregnancy and risks of oral clefts in newborns. Am J Epidemiol, Baltimore, v. 150 , no. 7, p. 683-694, Oct. 1999.

11. MENEGOTTO, B. G.; SALZANO F. M. Epidemiology of oral clefts in a large South American sample. Cleft Palate Craniofac J, Pittsburgh, v. 28, no. 4, p. 373-377, Oct. 1991

12. MURRAY, J. C. et al. Clinical and epidemiological studies of cleft lip and palate in the Philippines. Cleft Palate Craniofac J, Pittsburgh, v. 34, no. 1, p. 7-10, Jan. 1997.

13. NAGEM FILHO, H: MORAIS, N.: ROCHA, R. G. F. Contribuição para o estudo da prevalência das malformações congênitas labiopalatais na população escolar de Bauru. Rev Fac Odontol Univ São Paulo, São Paulo, v. 6, n. 2, p. 111-128, abr./jun. 1968.

14. RAJABIAN, M. H.; SHERKAT, M. An epidemiologic study of oral clefts in Iran: analysis of 1669 cases. Cleft Palate Craniofac J Pittsburgh, v. 37, no. 2, p. 191-196, Mar. 2000.

15. SLAVKIN, H. C. Incidence of cleft lips, palates rising. J Am Dent Assoc, Chicago, v. 123, no. 11, p. 61-65, Nov. 1992.
Endereço para correspondência

Patrícia Zambonato Freitas

Rua Silvio Marchione, 3-20 - Vila Universitária

17043-900 - Bauru - SP

E-mail: patzfreitas@uol.com.br 